\title{
Atomistic Insight into Cation Effects on Binding Energies in Cu-Catalyzed Carbon Dioxide Reduction
}

Ludwig, Thomas; Gauthier, Joseph A.; Dickens, Colin F.; Brown, Kristopher S.; Ringe, Stefan; Chan, Karen; Nørskov, Jens K.

Published in:

Journal of Physical Chemistry C

Link to article, DOI:

10.1021/acs.jpcc.0c07004

Publication date:

2020

Document Version

Peer reviewed version

Link back to DTU Orbit

Citation (APA):

Ludwig, T., Gauthier, J. A., Dickens, C. F., Brown, K. S., Ringe, S., Chan, K., \& Nørskov, J. K. (2020). Atomistic Insight into Cation Effects on Binding Energies in Cu-Catalyzed Carbon Dioxide Reduction. Journal of Physical Chemistry C, 124(45), 24765-24775. https://doi.org/10.1021/acs.jpcc.0c07004

\section{General rights}

Copyright and moral rights for the publications made accessible in the public portal are retained by the authors and/or other copyright owners and it is a condition of accessing publications that users recognise and abide by the legal requirements associated with these rights.

- Users may download and print one copy of any publication from the public portal for the purpose of private study or research.

- You may not further distribute the material or use it for any profit-making activity or commercial gain

- You may freely distribute the URL identifying the publication in the public portal 


\title{
Atomistic Insight into Cation Effects on Binding Energies in $\mathrm{Cu}$ - Catalyzed Carbon Dioxide Reduction
}

\author{
Thomas Ludwig, Joseph A. Gauthier, Colin F. Dickens, Kristopher S. Brown, Stefan Ringe, Karen Chan, \\ and Jens K. Nørskov*
}
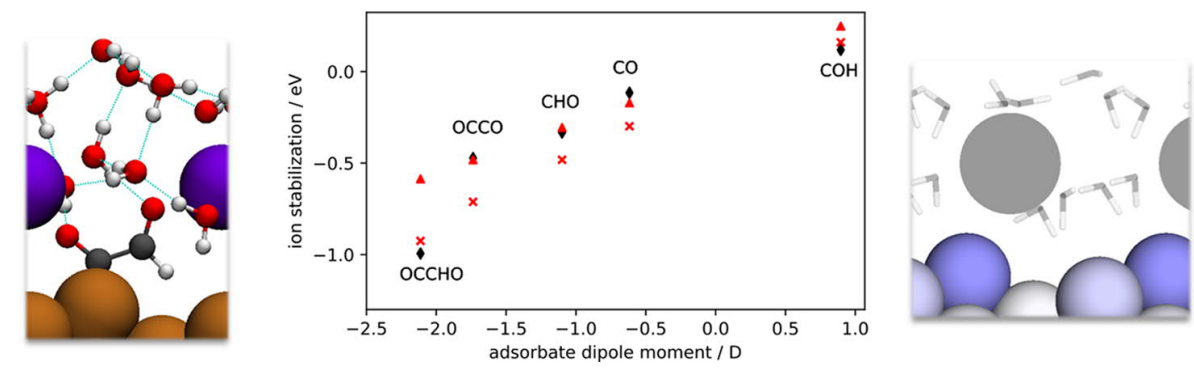

ABSTRACT: Electrolyte properties in general and electrolyte ions in particular have been shown to have significant effects on the kinetics of electrochemical $\mathrm{CO}_{2}$ and $\mathrm{CO}$ reduction at metal electrodes, but these effects have not yet been fully understood. We investigate the effects of cations at the aqueous electrolyte- $\mathrm{Cu}(211)$ interface on adsorbate binding energies and the electrolyte structure using density functional theory (DFT). Charging the interface via explicit $\mathrm{Na}^{+}$has systematic effects on adsorbateelectrolyte interactions and conformations. We describe specific local adsorbate-ion interactions, including direct alkali ionadsorbate coordination and hydrogen bonding via ion-coordinated water molecules. The relative importance of these specific interactions and purely electrostatic field-adsorbate interactions is investigated by comparing the DFT-calculated ion effects to those predicted by purely electrostatic models of the interface and the adsorbates. We find that the trend in ion effects among different adsorbates at constant surface charge density is well explained by a purely electrostatic interaction model. The binding energy of $\mathrm{OCCHO}$ is found to depend strongly on the surface charge density as well as the spatial distribution of ions at constant surface charge density. These effects are also explained by a purely electrostatic local electrostatic field-adsorbate model. This indicates that alkali ion effects can be mainly attributed to purely electrostatic field interactions and that the local field at ionstabilized active sites can depend significantly on both the overall charge density and on the spatial distribution of ions at constant charge density. This work provides new insight on alkali ion effects on a variety of adsorbates relevant to the $\mathrm{CO}_{2}$ and $\mathrm{CO}$ reduction reactions by describing specific local ion-adsorbate interactions, systematic changes in adsorbate-electrolyte interactions induced by explicit surface charge, and comparisons of the calculated effects on binding energies to simple electrostatic field-adsorbate models to explain trends among various adsorbates and at varying surface charge densities and supercell configurations.

\section{INTRODUCTION}

The challenge of efficient electrochemical energy conversion motivates current research on a variety of electrocatalytic processes. ${ }^{1}$ The electrocatalytic reduction of carbon dioxide ${ }^{2}$ has been the subject of much experimental and theoretical work. In particular, copper electrodes ${ }^{3-10}$ can catalyze $\mathrm{CO}_{2}$ and $\mathrm{CO}$ reduction to economically valuable hydrocarbons and oxygenates. ${ }^{11}$ Experimental studies have demonstrated the importance of the electrolyte in electrochemical reactions. For example, in mixed solvent electrolytes, the product distribution of $\mathrm{CO}_{2}{ }^{12}$ and nitrogen reduction ${ }^{13}$ strongly depends on the relative solvent concentrations. Experiments have demonstrated that the electrolyte $\mathrm{pH}^{14}$ and proton donor environment ${ }^{15,16}$ have a significant effect on the rate of proton-coupled electron transfer steps. There is evidence that local concentration gradients related to electrolyte transport properties also have significant effects on activity and selectivity of electrochemical reactions. ${ }^{15-21}$ Electrolyte ion effects have been experimentally observed to affect rates of electrode processes $^{22}$ including $\mathrm{CO}_{2}$ and $\mathrm{CO}$ reduction ${ }^{21,23-47}$ among other electrochemical reactions such as hydrogen evolution and oxygen reduction and evolution. ${ }^{48-55}$ 
These experimental observations motivated many theoretical studies on the interface between metals and aqueous electrolytes and its effects on electrochemical reactions. Classical force field methods have been applied both in the case of a neutral interface ${ }^{56-60}$ and charged interfaces with explicit ions. ${ }^{61-64}$ However, classical methods are not commonly applied to study metal surface reactions due to the difficulty of simultaneously describing electronic structure effects in the metal, chemical reactions and possible proton and electron transfer steps at the surface, and noncovalent interactions in the bulk. Therefore, theoretical studies commonly apply density functional theory (DFT) to study the aqueous electrochemical interface, with neutral charge ${ }^{65-69}$ and explicitly charged ${ }^{64,70-76}$ as well as various implicit solvent and hybrid methods including those which aim to fix the electrode or ion potentials. ${ }^{0,71,77-89}$ Various theoretical studies have examined solvation and ion or field effects on surface reactions, ${ }^{78}$ including electrochemical reactions such as hydrogen oxidation and evolution, ${ }^{90-95}$ oxygen evolution and reduction, ${ }^{96-102}$ and $\mathrm{CO}_{2} / \mathrm{CO}$ reduction. ${ }^{10,103-113}$

The effect of ions on binding energies at the electrochemical interface can be considered to have two possible contributions:

1. Electostatic field-adsorbate interactions, which depend only on the charge distribution at the electrochemical interface and on the interaction of the adsorbate with the resulting electrostatic field, and

2. Specific local interactions such as possible covalent bonding or complexation, which depend on detailed properties of the ion and adsorbate as well as any other electrolyte species involved.

Developing a more thorough understanding of these ion effects is a critical step toward the goal of engineering the electrochemical interface for optimal electrocatalysis performance. Ion effects have been examined in several previous theoretical studies on $\mathrm{CO}_{2}$ and $\mathrm{CO}$ reduction processes. It was found that for $\mathrm{CO}_{2}$ reduction to $\mathrm{CO}$ on noble metal electrodes, cations significantly stabilize the intermediates ${ }^{*} \mathrm{CO}_{2}$ and ${ }^{*} \mathrm{COOH} .{ }^{109}$ It was also found that cations significantly stabilize $\mathrm{C}_{2}$ intermediates on copper electrodes, providing insight on how cations influence the formation of $\mathrm{C}_{2}$ products. $^{38,106-108}$ In these studies, an electrostatic model based on the adsorbate dipole moment, polarizability, and an active site electric field of magnitude $\sim 1 \mathrm{~V} / \AA \AA$ has been shown to predict adsorbate stabilizations in reasonable agreement with the explicit ion DFT calculations. This provided evidence that alkali ion effects may be largely attributed to electrostatic field-adsorbate interactions rather than specific local interactions such as chemical bonding. Experiments have also consistently demonstrated that selectivity toward $\mathrm{C}_{2}$ products on $\mathrm{Cu}$ increases with increasing size of the alkali cation in the electrolyte, from $\mathrm{Li}^{+}$to $\mathrm{Cs}^{+} .24,37,38$ DFT calculation results determined that the electrostatic fields at active sites near isolated cations solvated at similar positions in the outer Helmholtz plane do not systematically depend on the cation size if the ion concentration is kept constant. ${ }^{38,107}$ Thus, the selectivity dependence on alkali cation size is hypothesized to be a result of an increased concentration of larger ions near the surface, ${ }^{24,37,38,114}$ though the size dependence of cation hydrolysis has also been considered as a factor contributing to alkali cation size effects. ${ }^{21}$ The possible role of adsorbatespecific local interactions has, in general, not been as thoroughly studied theoretically, although there is some evidence that specific local interactions may be important in electrolytes containing ionic liquid species ${ }^{29-33,104,115,116}$ and other additive species. ${ }^{34-36,39,117}$ Moreover, previous studies used a variety of methodologies to construct water structures and ion positions and for calculating and applying solvation corrections, complicating systematic comparisons among previous theoretical results. Finally, the exact nature of the dependence of adsorbate binding energies on the applied potential, and thus on the surface charge density, is still not completely understood.

The dependence of ion effects on applied potential or surface charge density is also an open question with important implications in kinetics. Some theoretical results ${ }^{118}$ indicated that the field stabilization at a cation-stabilized active site does not significantly depend on the overall surface coverage, and thus the effect of changing the applied potential is mainly to change the coverage of field-stabilized active sites rather than the local field at each individual active site. On the other hand, the experimentally determined dependence of vibrational modes on surface charge density ${ }^{119,120}$ and recent theoretical results ${ }^{114}$ provide evidence that active site fields and binding energies do indeed depend on the average surface charge density and thus the applied potential. The rates predicted from microkinetic models generally depend linearly on the active site coverage and exponentially on binding energies, underscoring the importance of this difference. Understanding how the ion effect depends on the average ion coverage or applied potential thus motivates the study of the interaction between ions and adsorbed species at the electrochemical interface.

Therefore, this work aims to study in further detail the structure and energetics associated with the interaction between an alkali metal cation and a variety of adsorbates. We use a DFT explicit solvent and ion model of the metal electrolyte interface coupled with a global minimization algorithm $^{121,122}$ to study the dependence of the free energies of adsorbed intermediates on the electrolyte structure. We describe specific local electrolyte-adsorbate interactions, including hydrogen bonding and adsorbate-ion coordination, and consider the effect of the explicit surface charge on these interactions. We consider a set of key adsorbed intermediates relevant to the $\mathrm{CO}_{2}$ and $\mathrm{CO}$ reduction reactions. The effect of the cation on the binding energies is compared to a capacitor model to evaluate the electrostatic field contribution. We perform a surface charge density dependence analysis on the binding energy of OCCHO by varying the simulation supercell size and thus the ion concentration. The surface charge density dependence results are compared with the capacitor model as well as a model incorporating the local field at the active site.

\section{COMPUTATIONAL DETAILS}

The Quantum ESPRESSO electronic structure suite ${ }^{123}$ was used for the DFT calculations, as was the Atomic Simulation Environment (ASE). ${ }^{124}$ The calculations used the Vanderbilt ultrasoft pseudopotentials ${ }^{125-128}$ and the dispersion-corrected Bayesian Error Estimation Functional BEEF-vdW. ${ }^{129-132}$ A plane wave basis was used for the valence electron representations and the Brillouin zone was sampled using a Monkhorst Pack grid. ${ }^{133}$ All relevant computational parameters were kept consistent with previous work on the uncharged $\mathrm{Cu}(211)$ surface $^{134}$ so that direct comparisons could be made. A modified version of the constrained minima hopping algorithm $^{121,122,124}$ was used for global optimization of 
adsorbate and electrolyte configurations. The harmonic approximation was used for free-energy corrections, and vibrational modes were found using the modules implemented in ASE. ${ }^{124}$ Atomistic visualizations were produced using pymol $^{135}$ and VMD. ${ }^{136}$ Further computational details are discussed in the Supporting Information (SI).

\section{RESULTS AND DISCUSSION}

We first describe the optimized electrolyte structure found at the charged $\mathrm{Cu}(211)$-electrolyte interface and describe electrolyte-adsorbate interactions with an emphasis on adsorbate-specific local interactions such as ion coordination and hydrogen bonding. The localization of surface charge and associated electrostatic field is discussed. The effects of the electrolyte structure on the adsorption energies of several adsorbed intermediates is described, and trends in these effects are identified and explained. The effect of varying surface charge density and spatial ion distributions on the OCCHO binding energy is evaluated using varying supercell sizes. Trends in the ion effects among various adsorbates as well as among varying charge densities and supercell configurations are identified and explained using electrostatic field-adsorbate interaction models.

Hydrogen Bonding, Ion Coordination, and Conformation Changes. The interactions of adsorbates with the local electrolyte environment via hydrogen bonding and ion coordination are shown in Table 1 . The corresponding global

Table 1. Ion Coordination and Hydrogen Bonding

$\begin{array}{lcccccc}\quad \text { adsorbate } & * & * \mathrm{CO} & * \mathrm{COH} & * \mathrm{CHO} & * \text { OCCO } & * \text { OCCHO } \\ \mathrm{HB}_{\text {accept }}^{\sigma=0} & & 0 & 0 & 1 & 2 & 2 \\ \mathrm{HB}_{\text {donate }}^{\sigma=0} & & 0 & 1 & 0 & 0 & 0 \\ \mathrm{HB}_{\text {accept }}^{\mathrm{Na}} & & 0 & 2 & 3 & 3 & 2 \\ \mathrm{HB}_{\mathrm{donate}}^{\mathrm{Na}} & & 0 & 0 & 0 & 0 & 0 \\ \mathrm{Na}^{+} \mathrm{O}-\mathrm{H} \cdots \mathrm{HB}_{\text {accept }} & & 0 & 2 & 2 & 2 & 1 \\ n_{\mathrm{Na}-\mathrm{O}_{\text {water }}} & 5 & 5 & 5 & 5 & 4 & 3 \\ n_{\mathrm{Na}-\mathrm{O}_{\text {ads }}} & & 1 & 0 & 0 & 1 & 2 \\ n_{\mathrm{Na}-\mathrm{O}} & 5 & 6 & 5 & 5 & 5 & 5 \\ \Delta_{0 \rightarrow \mathrm{Na}^{+}}\left(\mathrm{HB}_{\text {accept }}+\right. & & 1 & 3 & 2 & 2 & 2 \\ n_{\mathrm{Na}-\mathrm{O}_{\text {ads }}} & & & & & & \\ \left.\mathrm{HB}_{\text {donate }}\right) & & & & & & \end{array}$

minimal energy structures are shown in Figure 1. A hydrogen

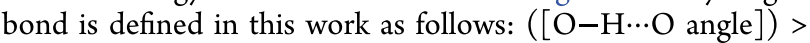
$145^{\circ}$ and $\mathrm{O} \cdots \mathrm{O}$ distance $<3.5 \AA$. Ion coordination is defined as a $\left(\mathrm{Na}^{+} \ldots \mathrm{O}\right)$ distance $<2.7 \AA$; further elaboration is provided in the SI.

Several abbreviations are used in Table 1 and the associated discussion. $\mathrm{HB}_{\text {accept }}^{\sigma=0}$ and $\mathrm{HB}_{\text {donate }}^{\sigma=0}$ are hydrogen bonds accepted and donated by an adsorbate in the uncharged configuration from previous work, ${ }^{134} \mathrm{HB}_{\text {accept }}^{\mathrm{Na}^{+}}$and $\mathrm{HB}_{\text {donate }}^{\mathrm{Na}^{+}}$are hydrogen bonds accepted and donated by an adsorbate in the explicitly charged configurations, and $\mathrm{Na}^{+} \mathrm{O}-\mathrm{H} \cdots \mathrm{HB}_{\text {accept }}$ are hydrogen bonds donated by waters directly coordinating the $\mathrm{Na}^{+}$ion. The coordination numbers $n_{\mathrm{Na}-\mathrm{O}_{\text {water }}} n_{\mathrm{Na}-\mathrm{O}_{\text {ads }}}$ and $n_{\mathrm{Na}-\mathrm{O}}$ are the number of water oxygen, adsorbate oxygen, and total oxygen atoms coordinating the $\mathrm{Na}^{+}$ion, respectively. Finally, $\Delta_{0 \rightarrow \mathrm{Na}^{+}}$ $\left(\mathrm{HB}_{\text {accept }}+n_{\mathrm{Na}-\mathrm{O}_{\text {ads }}}-\mathrm{HB}_{\text {donate }}\right)$ is the change in the sum of interaction numbers resulting from charging the interface with the explicit $\mathrm{Na}^{+}$ion, discussed further below.

Adsorbed $\mathrm{CO}, \mathrm{OCCO}$, and $\mathrm{OCCHO}$ directly coordinate the ion via oxygen atoms. DDEC bond order analysis ${ }^{137-140}$ detailed in the $\mathrm{SI}$ indicates that the $\mathrm{Na}^{+}-\mathrm{O}_{\text {adsorbate }}$ coordination interactions have similar bond orders to $\mathrm{Na}^{+}-\mathrm{O}_{\text {water }}$ interactions, with the exception of the $\mathrm{Na}^{+}-\mathrm{O}^{*}$ CO bond order, which is smaller than any other $\mathrm{Na}^{+}$-coordinated oxygen in this study, and is also the only case in which six oxygen atoms coordinate the $\mathrm{Na}^{+}$rather than five. In general, all of the adsorbates are more hydrogen bond accepting and less hydrogen bond donating relative to the uncharged configurations, ${ }^{134}$ with the exception of $\mathrm{CO}$ and OCCHO, which directly coordinate the $\mathrm{Na}^{+}$cation, hindering possible hydrogen bond accepting sites. Of the adsorbates studied, only $\mathrm{COH}$ has hydrogen bond donating capacity, and while it donates a hydrogen bond in the uncharged case, at the negatively charged interface, it does not donate any and accepts two; therefore, there is relatively little data on hydrogen bond donating adsorbates in our study. To more generally summarize the local electrolyte-adsorbate interactions, the positively polarized $\mathrm{H}$ atom in a water molecule and the positively charged $\mathrm{Na}^{+}$ion can both be classified as positively charged electrolyte species and the negatively polarized $\mathrm{O}$ atom in a water molecule can be classified as a negatively charged electrolyte species. Thus, the quantity $\left(\mathrm{HB}_{\text {accept }}+\right.$ $\left.n_{\mathrm{Na}-\mathrm{O}_{\text {ads }}}-\mathrm{HB}_{\text {donate }}\right)$ summarizes the balance of adsorbate interactions with positive and negative electrolyte species, and its change from the neutral to the charged interface denoted by $\Delta_{0 \rightarrow \mathrm{Na}^{+}}(\cdots)$ indicates that all adsorbates exhibit increased interactions with positive electrolyte species $\left(\mathrm{HB}_{\text {accept }}\right.$ and $\left.n_{\mathrm{Na}-\mathrm{O}_{\mathrm{ads}}}\right)$ and decreased interactions with negative electrolyte

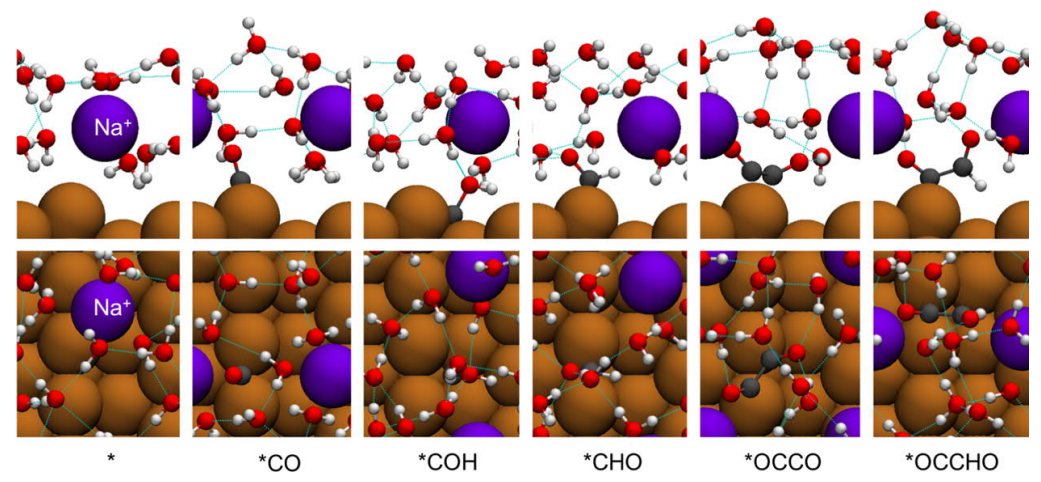

Figure 1. Global optimal structures of several solvated adsorbed intermediates in the presence of explicit $\mathrm{Na}^{+}$on $\mathrm{Cu}(211)$. 


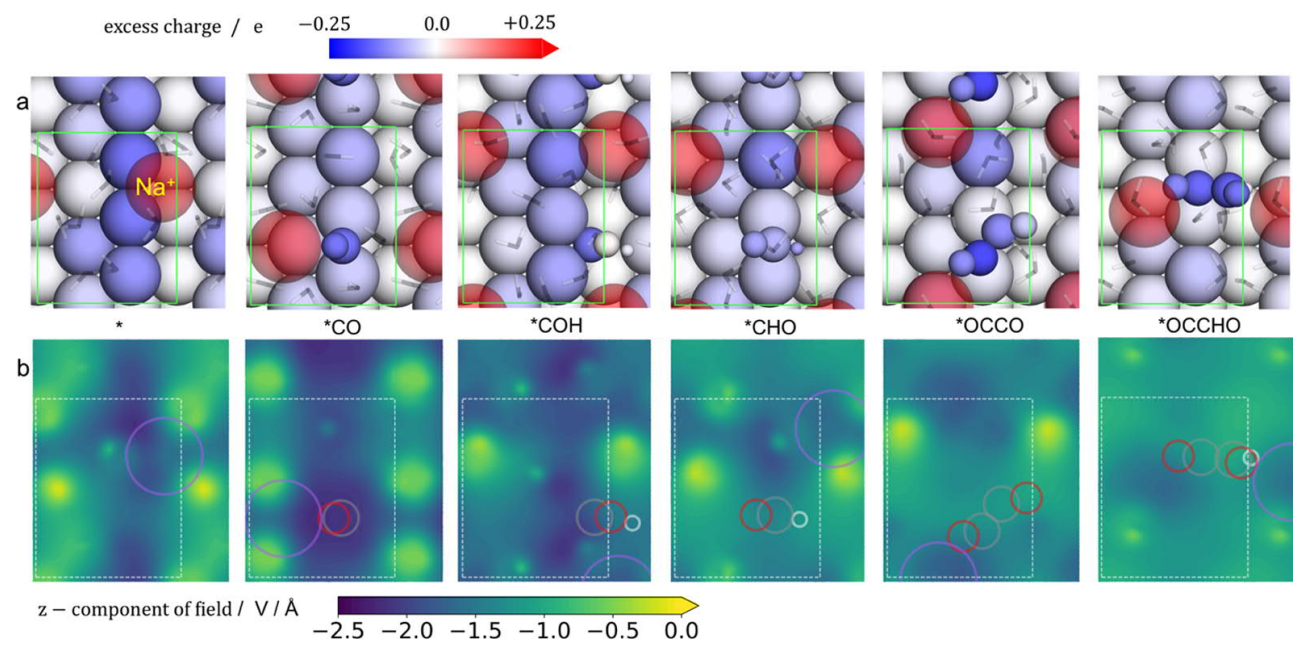

Figure 2. (a) Change in partial atomic charge on the surface and adsorbed intermediate atoms induced by $\mathrm{Na}^{+}$on $\mathrm{Cu}(211)$, as calculated by $\mathrm{Bader}$ analysis. (b) $z$-component of electrostatic field induced by $\mathrm{Na}^{+}$on $\mathrm{Cu}(211)$. The partial atomic charge on $\mathrm{Na}^{+}$is $\approx 0.9 e$ in all cases.
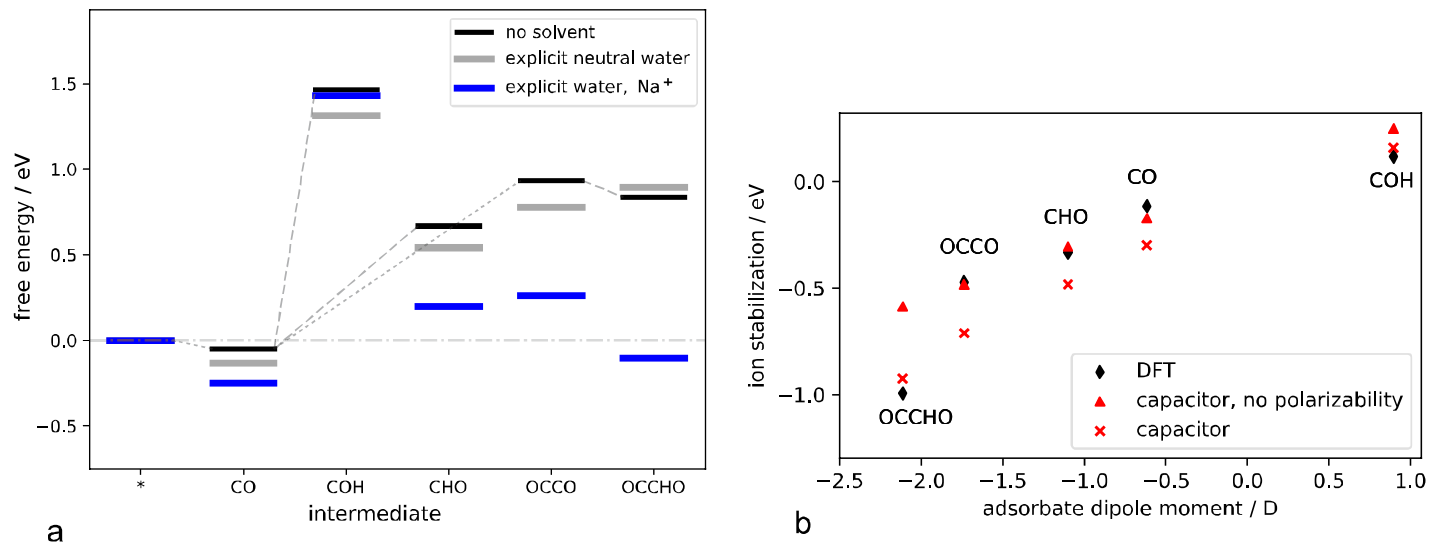

Figure 3. (a) Free energies of binding of adsorbed intermediates in vacuum, water with no explicit ions, and water with explicit $\mathrm{Na}^{+}$ions included at a surface charge density of approximately $0.33 \mathrm{C} / \mathrm{m}^{2}$. "Explicit neutral water" and "no solvent" comparison data are taken from previous work. ${ }^{134}$ All free-energy diagrams shown here represent the CHE result at $0 \mathrm{~V}$ vs RHE but the explicit $\mathrm{Na}^{+}$result includes the effect of the explicit surface charge. (b) Ion stabilization and comparison to the capacitor model.

species $\left(\mathrm{HB}_{\text {donate }}\right)$ relative to the results at the uncharged interface.

Adsorbate conformation changes are particularly apparent in $\mathrm{COH}$, in which the $\mathrm{CO}-\mathrm{H}$ flips to point toward the surface relative to its uncharged conformation, and in OCCHO, in which the $\mathrm{O}$ of the $-\mathrm{CO}$ fragment desorbs from the step edge and the $\mathrm{H}$ of the $\mathrm{C}-\mathrm{H}$ fragment approaches the terrace more closely by $\sim 1 \AA$ relative to the uncharged conformation. When no adsorbate is present, the $\mathrm{Na}^{+}$ion is coordinated with five water molecules, coordinated via the oxygen atom with $\mathrm{Na}^{+}-$ $\mathrm{O}-\mathrm{H}$ bisector angles between approximately 110 and $125^{\circ}$. This coordination number is consistent with previously reported bulk water- $\mathrm{Na}^{+}$coordination values of between 4 and $6 .^{141,142}$ There is no specific adsorption of water or $\mathrm{Na}^{+}$on the $\mathrm{Cu}(211)$ surface in any case, in contrast with previous results, which showed a $1 / 3$ coverage of water on the step sites at the uncharged interface, ${ }^{134}$ and the orientation of water molecules near the surface is predominantly hydrogen-down due to their interaction with the electrostatic field. The decrease in coverage of $\mathrm{O}$-adsorbed water and increasingly $\mathrm{H}$ down orientation of water molecules at more reducing potentials, especially negative of the PZC, are consistent with previous results. ${ }^{143-145}$ We note here that a rough estimate of the applied potential corresponding to the calculations in this work is between -0.7 and $-1.3 \mathrm{~V}$ vs SHE. The PZC of low index facets of copper in water has been experimentally found to be approximately $-0.7 \mathrm{~V}$ vs SHE; ${ }^{146}$ this work is concerned with negatively charged surfaces, corresponding to potentials negative of -0.7 vs SHE. The work functions of the global minima we report for the no-adsorbate, $\mathrm{CO}$, and $\mathrm{COH}$ states are $3.65,3.10$, and $3.06 \mathrm{eV}$, respectively, corresponding roughly to applied voltages between -0.7 and $-1.3 \mathrm{~V}$ vs SHE, respectively, ${ }^{147}$ corroborating the potential ranges suggested by the surface charge. Further precision in the applied potential is difficult due to the strong effects of the water orientation and adsorbate dipoles on the calculated work functions. ${ }^{148}$ We also note that the results reported in this work do not consider the possible effects of thermal motion at ambient conditions, which may affect the distribution of hydrogen bonding and ion coordination. Recent results from ab initio molecular dynamics at $300 \mathrm{~K}^{77}$ demonstrated that thermally averaged hydrogen bonding statistics and other structural features are comparable to those described by static structures, ${ }^{134}$ with the caveat that there are significant instantaneous thermal fluctuations in these 
quantities in the dynamic simulations at ambient conditions. This gives reason to expect that the results reported in this work provide meaningful physical insight into the structures and interactions at the charged interface and provide guidance for more detailed future work, incorporating the effects of thermal fluctuations.

Localization of Excess Surface Charge. The hydrogen bonding, ion coordination, and conformation behavior shown in Table 1 can be attributed to the localization of excess surface charge and the resulting electrostatic field. Single-point calculations on the globally optimal structures were carried out with and without the cation to determine the location of the excess surface charge, and the resulting interfacial electrostatic fields, induced by the presence of the cation. Bader charge analysis ${ }^{149-152}$ was used to partition the charge density, and the electrostatic field calculations are further described in the SI. The results are shown in Figure 2.

Figure 2a shows that for the clean surface, the excess charge is mostly localized on the step edge sites, which is consistent with the tendency of sharp surface features to accumulate charge due to classical electrostatics and with previous work demonstrating that ion concentrations and surface charge are enhanced at sharply structured sites. ${ }^{111}$ Figure 2a also shows that for all adsorbates considered, a significant amount of excess negative surface charge is localized in the adsorbate atoms. This provides an explanation for the adsorbateelectrolyte interaction behavior shown in Table 1 . Figure $2 \mathrm{~b}$ shows the effect of this charge localization on the electrostatic field averaged over the region above the electrode, as described in the SI. The average electrostatic field magnitude in these cells is approximately $1.4 \mathrm{~V} / \AA$, and is enhanced near the ion and also along the step edges.

Cation Effect on Binding Energies for $\mathrm{CO}_{2}$ Reduction Intermediates. The effect of the explicit $\mathrm{Na}^{+}$ion on various adsorbed intermediate binding energies was evaluated by comparing the binding energies obtained including the explicit $\mathrm{Na}^{+}$and water in the model to the energies obtained in vacuum and with explicit neutral water from previous work. ${ }^{134}$ The free binding energy results are shown in Figure 3.

Figure 3 shows that the effect of the explicit ion on the binding energies can be quite large, up to $\sim 1 \mathrm{eV}$ as in the case of *OCCHO. This is in contrast to the previously found solvation effects with neutral water, which were relatively smaller, at most approximately $0.25 \mathrm{eV},{ }^{134}$ and is also consistent with previous results which demonstrated largeion and field effects in stabilizing $C_{2}$ species ${ }^{105-108,110}$ and other species such as adsorbed $\mathrm{CO}_{2} .{ }^{104}$ We define this ion stabilization $\Delta G_{\text {stabilize }}^{\mathrm{Na}^{+}}$in eq 1 as the difference in binding energies with and without the explicit $\mathrm{Na}^{+}$

$$
\Delta G_{\text {stabilize }}^{\mathrm{Na}^{+}}=\Delta G_{\text {bind }}^{\mathrm{Na}^{+}}-\Delta G_{\text {bind }}^{\text {neutral water }}
$$

where $\Delta G_{\text {bind }}^{\mathrm{Na}^{+}}$is the binding energy in the explicit water with $\mathrm{Na}^{+}$and $\Delta G_{\text {bind }}^{\text {neutral water }}$ is the binding energy with explicit neutral water, which was calculated in previous work. ${ }^{134}$ This ion effect on the binding energy $\Delta G_{\text {stabilize }}^{\mathrm{Na}^{+}}$may have contributions from specific local interactions, such as those described in Table 1 , in addition to a purely electrostatic fieldadsorbate interaction, as shown in eq 2

$$
\Delta G_{\text {stabilize }}^{\mathrm{Na}^{+}}=\Delta G_{\text {stabilize }}^{\text {field }}+\Delta G_{\text {stabilize }}^{\text {specific local interactions }}
$$

where all effects not explained by purely electrostatic field effects are incorporated into the specific local interaction term. To investigate these contributions, we compare the results expected from a purely electrostatic interaction to the total effect from the DFT results. The effect of an external electric field on the energy of a polarizable dipole, assuming only the $z$ component is significant, is given by eq 3

$$
\Delta G_{\text {stabilize }}^{\text {field }}=-\mu_{0, z} E_{z}-\frac{\alpha}{2} E_{z}^{2}
$$

where $\Delta G_{\text {stabilize }}^{\text {field }}$ is the energy change due to an electrostatic field of magnitude $E_{z}$ on a dipole with dipole moment $\mu_{0, z}$ and polarizability $\alpha$. The dipole moment vector is by convention directed from the negative charge end to the positive charge end of the dipole, resulting in the sign convention used here, and the $z$-direction is taken to be the direction normal to the metal surface. The dipole moments and polarizabilities for all adsorbates in this work were obtained by calculating $\Delta G_{\text {stabilize }}^{\text {field }}$ for the bound adsorbates with no solvent or ions present as a function of the applied electrostatic field, and then fitting the model described by eq 3 to this data by optimizing the values of $\mu_{0, z}$ and $\alpha$; this is further elaborated in the SI. Uniform capacitor models of the electrochemical interface have been shown to be a useful approximation in many applications. ${ }^{94,95}$ A uniform parallel-plate capacitor model relates the surface charge density to the electrostatic field at the interface, as shown in eq 4

$$
E_{z, \text { capacitor }}^{\text {uniform }}=-\frac{\sigma_{\text {electrolyte }}}{\epsilon}
$$

where $\sigma$ is the excess surface charge density of the electrolyte phase (here, the sign convention is such that excess $\mathrm{Na}^{+}$ions in the electrolyte at the electrochemical interface result in a positive value of $\left.\sigma_{\text {electrolyte }}\right), \epsilon$ is the permittivity, and the sign convention for the field $E_{z \text {,capacitor }}^{\text {uniform }}$ is that electrostatic field lines directed perpendicular outward from the metal surface correspond to a positive value of $E_{z}$. We will refer to this model as the uniform capacitor model, or simply the capacitor model, for brevity.

Figure $3 \mathrm{~b}$ shows the ion stabilization $\Delta G_{\text {stabilize }}^{\mathrm{Na}^{+}}$as defined in eq 1 and calculated using the data displayed in Figure 3a for each adsorbate considered. The energetic data in Figure $3 \mathrm{~b}$ are all calculated at the same excess surface charge density of approximately $0.33 \mathrm{C} / \mathrm{m}^{2}$ if each $\mathrm{Na}^{+}$ion is taken to be of integer $1 e$ charge. The electrostatic field resulting from this surface charge density, in the parallel-plate capacitor model, depends on the permittivity, as shown in eq 4 . In this work, we calculated an effective relative permittivity of $\epsilon_{\mathrm{r}} \approx 2.8$ by fitting a line representing eq 4 to the average field and surface charge density data, as shown in the SI. The assumption that each ion has integer charge in the simulation cell is not exact, ${ }^{118}$ but the convention allows for comparison at a consistent surface ion concentration among all adsorbates considered. The capacitor model results, as calculated by eq 3 , are shown in Figure $3 \mathrm{~b}$. The results with and without the polarizability term are plotted to demonstrate the relative significance of the polarizability. Note that the capacitor model was used to predict the stabilizations given only the relative permittivity and the dipole moments and polarizabilities of the adsorbates; the model parameters were not merely fit to the stabilization energies from DFT. This evaluates whether the ion stabilizations can be accurately predicted using only the average electrostatic field or the permittivity value, dipole moments, and polarizabilities. 

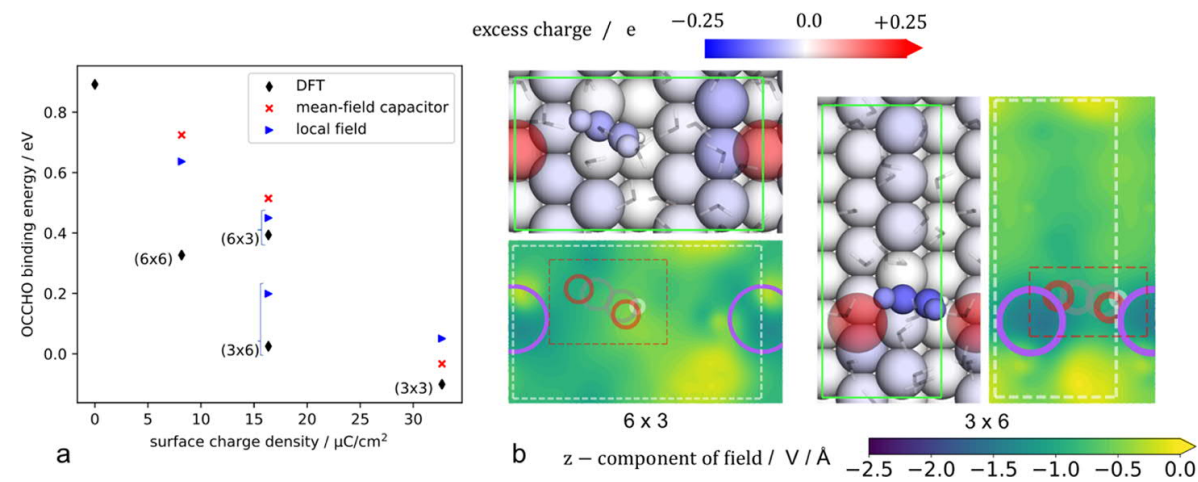

Figure 4. (a) * OCCHO binding energy dependence on explicit surface charge density with comparison to the capacitor and local field models. (b) Visualization of change in the partial atomic charge on the surface and adsorbed intermediate atoms induced by the $\mathrm{Na}^{+}$ion, as calculated by $\mathrm{Bader}$ analysis, and $z$-component of the electrostatic field, induced by the $\mathrm{Na}^{+}$ion on $\mathrm{Cu}(211)$ for several supercell shapes. The partial atomic charge on $\mathrm{Na}^{+}$is $\approx 0.9 e$ in all cases.

This allows the results to be extended to other adsorbates as long as their dipole moments and polarizabilities are known, as well as to systems which may have different permittivity values.

The results from the capacitor model are in relatively close agreement with the DFT results, indicating that the $\mathrm{Na}^{+}$ion effect can largely be attributed to a field-adsorbate interaction and that the trend among adsorbates at the given charge density can be accurately understood purely by electrostatics. The capacitor model and permittivity used here give an average electrostatic field of $\sim-1.4 \mathrm{~V} / \AA$, which is similar to previously reported field magnitudes. ${ }^{88,104,107}$ Although the overall trend is predicted by the capacitor model, the remaining deviations may be due to variations in the local electrostatic field ${ }^{63,88,104,107,111}$ or due to local interactions such as those shown in Table 1 , all of which are ignored in the purely electrostatic model. This analysis provides further evidence that despite the presence of specific local electrolyteadsorbate interactions shown in Table 1 , the overall trends in alkali ion effects on adsorbate binding energies can be attributed to the electrostatic field-adsorbate interaction.

Dependence of Binding Energy on Surface Charge Density. To investigate the dependence of adsorption energies on ion surface charge density, minima hopping calculations were carried out to find low-energy minima for lower surface charge densities in several larger simulation supercells for the OCCHO adsorbate. The results of the surface charge density dependence are shown in Figure 4a.

There are two immediately apparent discrepancies between the DFT results and the uniform capacitor model predictions. The $3 \times 6$ and $6 \times 3$ supercells are at the same surface charge density, so in the capacitor model, these configurations are expected to be stabilized by an identical amount. But as shown in Figure $4 a$, the $3 \times 6$ supercell binding energy is more negative than that of the $6 \times 3$ supercell by approximately 0.4 eV. Furthermore, it is evident in Figure 4a that the uniform capacitor model, which contains the assumption that the field is uniform over the entire supercell, performs well for the high surface charge density $3 \times 3$ supercell but significantly underpredicts the stabilization for lower charge densities. We investigate the possible origin of these discrepancies by studying the local electrolyte environment of the adsorbates in more detail.

Figure $4 \mathrm{~b}$ shows the global minimum configurations of $\mathrm{OCCHO}$ in the relevant supercell configurations. In particular, in the $3 \times 6$ supercell, both oxygens of OCCHO coordinate an ion due to the relatively small distance between ions in the direction perpendicular to the step edge. In the $6 \times 3$ supercell, neither oxygen directly coordinates the ion, though one oxygen accepts a hydrogen bond from ion-coordinated water. This indicates a possible difference in specific local ion-adsorbate interactions.

To isolate the effect of the electrostatic field-adsorbate interaction, we define a "local" rectangular region with $1.5 \AA$ margins around the adsorbate atoms and average the electrostatic field, in the absence of the adsorbate, over this region. Details are given in the SI. The expected stabilizations from this local field are shown in Figure 4 a labeled as the "local field". This local electrostatic field-adsorbate interaction model explains the relative differences between the $3 \times 3,6$ $\times 3$, and $3 \times 6$ configurations, and improves the agreement with DFT results for the $6 \times 6$ supercell, though the stabilizations are generally still underpredicted. Various other methods of estimating the effective local electrostatic field in the region near the adsorbate were considered as described in the SI, some of which overpredict the stabilizations, but all methods considered give the same trends as the one shown in Figure 4a.

The local electrostatic field correctly explains the trends in the explicit ion/solvent DFT results, providing further evidence that the electrostatic field-adsorbate interaction is relatively more energetically significant than specific $\mathrm{Na}^{+}$ionadsorbate interactions (such as oxygen $-\mathrm{Na}^{+}$coordination and hydrogen bonding effects) for alkali ions. The results also indicate that even at constant surface charge density, the details of the spatial distribution of ions around an active site can have significant effects on the local field and thus the binding energies of intermediates. It is thus important to consider the effect of variations in the geometric distribution of ions on the local electrostatic field, even at a given ion coverage. In summary, the local field and the resulting binding energy of $\mathrm{OCCHO}$ are sensitive not only to the surface charge density but also to the geometric distribution of surface charge at a given charge density, and in all cases, this dependence can be attributed to the local electrostatic field in the vicinity of the adsorbate. Due to the large computational expense of optimizing electrolyte structures in the larger supercells required, we only investigated these surface charge density and local field effects for OCCHO, the adsorbate with the largest field effect in the smaller supercells, as shown in Figure 3. We expect that the effects of surface charge density and local 
electrostatic field just discussed for OCCHO also hold true for the other adsorbates considered because both the trend among adsorbates at constant charge density in Figure 3 and the dependence on the local field of OCCHO in Figure 4 are explained by the same field-dipole and polarizability interactions described in eq 3 . Our results indicate that capacitor models, commonly used to approximate field effects in microkinetic models, can accurately describe trends among various adsorbates at a given charge density, especially at higher charge densities, at which the field is fairly uniform. However, the significant variations in the local electrostatic field at low charge densities, due to the discrete nature of ions, result in potentially nonlinear dependence of the local electrostatic field on surface charge density. Therefore, future work is warranted in clarifying the dependence of the effective electrostatic field on the charge density, and thus on the applied potential. The results for adsorbed intermediates provided by this study should also provide guidance for future studies on transition states and associated reaction barriers, which are critical for complete kinetic models of electrochemical processes.

\section{CONCLUSIONS}

In this work, the effect of explicit excess surface charge on the binding energies and local electrolyte structure associated with solvated adsorbed intermediates relevant to $\mathrm{CO}_{2}$ and $\mathrm{CO}$ reduction on $\mathrm{Cu}(211)$ was investigated using DFT. We find that the excess surface charge localizes primarily on the step edge and on the adsorbates, and the associated electrostatic field has a significant effect on the interfacial water structure and the adsorbate conformations and binding energies. The water structure is predominantly hydrogen-down; there is no water or $\mathrm{Na}^{+}$adsorption on the $\mathrm{Cu}$ surface, and the adsorbates accept more hydrogen bonds and cation coordination from the electrolyte at the charged interface relative to the neutral conformations. The effect of $\mathrm{Na}^{+}$on the binding energies of all globally minimized adsorbates can be largely attributed to purely electrostatic field interactions, despite the presence of changes in the specific local adsorbate-electrolyte interactions such as hydrogen bonding and ion coordination. The trend in adsorbate stabilizations among all adsorbates considered, at constant surface charge density, is predicted using a parallelplate capacitor model of the charged interface. The binding energy of OCCHO was shown to depend strongly on surface charge density and also on geometric charge distribution even at constant surface charge density. The local electrostatic field in the vicinity of the adsorbate was found to accurately explain the dependence of adsorbate binding energy on surface charge density and spatial distribution of ions. These results provide insight into the relative significance of specific local adsorbateelectrolyte interactions and electrostatic field-adsorbate interactions for the case of alkali ions such as $\mathrm{Na}^{+}$. The results also shed light on how the active site electrostatic field and thus the adsorbate binding energies depend on the surface charge density and the spatial distribution of ions at the interface.

\section{AUTHOR INFORMATION}

\section{Corresponding Author}

Jens K. Nørskov - Department of Physics, Technical University of Denmark, 2800 Kongens Lyngby, Denmark; ๑ orcid.org/ 0000-0002-4427-7728; Email: jkno@fysik.dtu.dk

\section{Authors}

Thomas Ludwig - SUNCAT Center for Interface Science and Catalysis, SLAC National Accelerator Laboratory, Menlo Park, California 94025, United States; SUNCAT Center for Interface Science and Catalysis, Department of Chemical Engineering, Stanford University, Stanford, California 94305, United States; (1) orcid.org/0000-0002-2921-0488

Joseph A. Gauthier - SUNCAT Center for Interface Science and Catalysis, SLAC National Accelerator Laboratory, Menlo Park, California 94025, United States; SUNCAT Center for Interface Science and Catalysis, Department of Chemical Engineering, Stanford University, Stanford, California 94305, United States; O orcid.org/0000-0001-9542-0988

Colin F. Dickens - SUNCAT Center for Interface Science and Catalysis, SLAC National Accelerator Laboratory, Menlo Park, California 94025, United States; SUNCAT Center for Interface Science and Catalysis, Department of Chemical Engineering, Stanford University, Stanford, California 94305, United States;

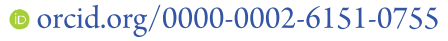

Kristopher S. Brown - SUNCAT Center for Interface Science and Catalysis, SLAC National Accelerator Laboratory, Menlo Park, California 94025, United States; SUNCAT Center for Interface Science and Catalysis, Department of Chemical Engineering, Stanford University, Stanford, California 94305, United States; ○ orcid.org/0000-0002-9374-9138

Stefan Ringe - Department of Energy Science \& Engineering, DGIST, Daegu 42988, Republic of Korea; 이이.org/00000002-7804-1406

Karen Chan - Department of Physics, Technical University of Denmark, 2800 Kongens Lyngby, Denmark; 이이.org/ 0000-0002-6897-1108

Notes

The authors declare no competing financial interest.

\section{ACKNOWLEDGMENTS}

T.L. acknowledges support from the United States Department of Energy through the Computational Sciences Graduate Fellowship (DOE CSGF) under grant number DE-FG0297ER25308. This material is based upon work performed by the Joint Center for Artificial Photosynthesis, a DOE Energy Innovation Hub, supported through the Office of Science of the U.S. Department of Energy under Award Number DESC0004993. C.F.D. acknowledges fellowship support from the National Science Foundation Graduate Research Fellowship 
(Grant No. DGE-114747). K.S.B. was supported by the Department of Defense (DoD) through the National Defense Science \& Engineering Graduate Fellowship (NDSEG) Program. K.C. and J.K.N. acknowledge a research grant (9455) from "VILLUM FONDEN." Some of the computing for this project was performed on the Sherlock cluster (Stanford Research Computing Center). We would like to thank Stanford University and the Stanford Research Computing Center for providing computational resources and support that contributed to these research results.

\section{REFERENCES}

(1) Seh, Z. W.; Kibsgaard, J.; Dickens, C. F.; Chorkendorff, I.; Nørskov, J. K.; Jaramillo, T. F. Combining theory and experiment in electrocatalysis: Insights into materials design. Science 2017, 355, No. eaad4998.

(2) Mikkelsen, M.; Jørgensen, M.; Krebs, F. C. The teraton challenge. A review of fixation and transformation of carbon dioxide. Energy Environ. Sci. 2010, 3, 43-81.

(3) Hori, Y.; Kikuchi, K.; Suzuki, S. Production of $\mathrm{CO}$ and $\mathrm{CH} 4$ in electrochemical reduction of $\mathrm{CO} 2$ at metal electrodes in aqueous hydrogencarbonate solution. Chem. Lett. 1985, 14, 1695-1698.

(4) Kuhl, K. P.; Cave, E. R.; Abram, D. N.; Jaramillo, T. F. New insights into the electrochemical reduction of carbon dioxide on metallic copper surfaces. Energy Environ. Sci. 2012, 5, 7050-7059.

(5) Schouten, K.; Kwon, Y.; Van der Ham, C.; Qin, Z.; Koper, M. A new mechanism for the selectivity to $\mathrm{C} 1$ and $\mathrm{C} 2$ species in the electrochemical reduction of carbon dioxide on copper electrodes. Chem. Sci. 2011, 2, 1902-1909.

(6) Hahn, C.; Hatsukade, T.; Kim, Y.-G.; Vailionis, A.; Baricuatro, J. H.; Higgins, D. C.; Nitopi, S. A.; Soriaga, M. P.; Jaramillo, T. F. Engineering $\mathrm{Cu}$ surfaces for the electrocatalytic conversion of $\mathrm{CO} 2$ : Controlling selectivity toward oxygenates and hydrocarbons. Proc. Natl. Acad. Sci. U.S.A. 2017, 114, 5918-5923.

(7) Peterson, A. A.; Abild-Pedersen, F.; Studt, F.; Rossmeisl, J.; Nørskov, J. K. How copper catalyzes the electroreduction of carbon dioxide into hydrocarbon fuels. Energy Environ. Sci. 2010, 3, 13111315.

(8) Li, C. W.; Kanan, M. W. CO2 reduction at low overpotential on $\mathrm{Cu}$ electrodes resulting from the reduction of thick $\mathrm{Cu} 2 \mathrm{O}$ films. J. Am. Chem. Soc. 2012, 134, 7231-7234.

(9) Calle-Vallejo, F.; Koper, M. T. Theoretical considerations on the electroreduction of $\mathrm{CO}$ to $\mathrm{C} 2$ species on $\mathrm{Cu}(100)$ electrodes. Angew. Chem., Int. Ed. 2013, 52, 7282-7285.

(10) Liu, X.; Xiao, J.; Peng, H.; Hong, X.; Chan, K.; Nørskov, J. K. Understanding trends in electrochemical carbon dioxide reduction rates. Nat. Commun. 2017, 8, No. 15438.

(11) Nitopi, S.; Bertheussen, E.; Scott, S. B.; Liu, X.; Engstfeld, A. K.; Horch, S.; Seger, B.; Stephens, I. E.; Chan, K.; Hahn, C.; et al. Progress and perspectives of electrochemical $\mathrm{CO} 2$ reduction on copper in aqueous electrolyte. Chem. Rev. 2019, 119, 7610-7672.

(12) Tomita, Y.; Teruya, S.; Koga, O.; Hori, Y. Electrochemical reduction of carbon dioxide at a platinum electrode in acetonitrilewater mixtures. J. Electrochem. Soc. 2000, 147, 4164-4167.

(13) Tsuneto, A.; Kudo, A.; Sakata, T. Lithium-mediated electrochemical reduction of high pressure $\mathrm{N} 2$ to NH3. J. Electroanal. Chem. 1994, 367, 183-188.

(14) Strmcnik, D.; Uchimura, M.; Wang, C.; Subbaraman, R.; Danilovic, N.; Van Der Vliet, D.; Paulikas, A. P.; Stamenkovic, V. R.; Marković, N. M. Improving the hydrogen oxidation reaction rate by promotion of hydroxyl adsorption. Nat. Chem. 2013, 5, 300.

(15) Wuttig, A.; Yoon, Y.; Ryu, J.; Surendranath, Y. Bicarbonate is not a general acid in Au-catalyzed CO2 electroreduction. J. Am. Chem. Soc. 2017, 139, 17109-17113.

(16) Ryu, J.; Wuttig, A.; Surendranath, Y. Quantification of Interfacial $\mathrm{pH}$ Variation at Molecular Length Scales Using a Concurrent Non-Faradaic Reaction. Angew. Chem., Int. Ed. 2018, 57, 9300-9304.
(17) Hall, A. S.; Yoon, Y.; Wuttig, A.; Surendranath, Y. Mesostructure-induced selectivity in $\mathrm{CO} 2$ reduction catalysis. J. Am. Chem. Soc. 2015, 137, 14834-14837.

(18) Yoon, Y.; Hall, A. S.; Surendranath, Y. Tuning of silver catalyst mesostructure promotes selective carbon dioxide conversion into fuels. Angew. Chem., Int. Ed. 2016, 55, 15282-15286.

(19) Singh, M. R.; Goodpaster, J. D.; Weber, A. Z.; Head-Gordon, M.; Bell, A. T. Mechanistic insights into electrochemical reduction of $\mathrm{CO} 2$ over Ag using density functional theory and transport models. Proc. Natl. Acad. Sci. U.S.A. 2017, 114, E8812-E8821.

(20) Raciti, D.; Mao, M.; Park, J. H.; Wang, C. Local pH effect in the $\mathrm{CO} 2$ reduction reaction on high-surface-area copper electrocatalysts. J. Electrochem. Soc. 2018, 165, F799-F804.

(21) Singh, M. R.; Kwon, Y.; Lum, Y.; Ager, J. W., III; Bell, A. T. Hydrolysis of electrolyte cations enhances the electrochemical reduction of $\mathrm{CO} 2$ over $\mathrm{Ag}$ and $\mathrm{Cu}$. J. Am. Chem. Soc. 2016, 138, 13006-13012.

(22) Frumkin, A. Influence of cation adsorption on the kinetics of electrode processes. Trans. Faraday Soc. 1959, 55, 156-167.

(23) Paik, W.; Andersen, T.; Eyring, H. Kinetic studies of the electrolytic reduction of carbon dioxide on the mercury electrode. Electrochim. Acta 1969, 14, 1217-1232.

(24) Murata, A.; Hori, Y. Product selectivity affected by cationic species in electrochemical reduction of $\mathrm{CO} 2$ and $\mathrm{CO}$ at a $\mathrm{Cu}$ electrode. Bull. Chem. Soc. Jpn. 1991, 64, 123-127.

(25) Thorson, M. R.; Siil, K. I.; Kenis, P. J. Effect of cations on the electrochemical conversion of $\mathrm{CO} 2$ to CO. J. Electrochem. Soc. 2013, 160, F69-F74.

(26) Stoffelsma, C.; Rodriguez, P.; Garcia, G.; Garcia-Araez, N.; Strmcnik, D.; Marković, N. M.; Koper, M. T. Promotion of the oxidation of carbon monoxide at stepped platinum single-crystal electrodes in alkaline media by lithium and beryllium cations. J. Am. Chem. Soc. 2010, 132, 16127-16133.

(27) Pérez-Gallent, E.; Marcandalli, G.; Figueiredo, M. C.; CalleVallejo, F.; Koper, M. T. Structure-and potential-dependent cation effects on $\mathrm{CO}$ reduction at copper single-crystal electrodes. J. Am. Chem. Soc. 2017, 139, 16412-16419.

(28) Kaneco, S.; Iiba, K.; Katsumata, H.; Suzuki, T.; Ohta, K. Effect of sodium cation on the electrochemical reduction of $\mathrm{CO} 2$ at a copper electrode in methanol. J. Solid State Electrochem. 2007, 11, 490-495.

(29) Rosen, B. A.; Salehi-Khojin, A.; Thorson, M. R.; Zhu, W.; Whipple, D. T.; Kenis, P. J.; Masel, R. I. Ionic liquid-mediated selective conversion of $\mathrm{CO} 2$ to $\mathrm{CO}$ at low overpotentials. Science 2011, 334, 643-644.

(30) Rosen, B. A.; Haan, J. L.; Mukherjee, P.; Braunschweig, B.; Zhu, W.; Salehi-Khojin, A.; Dlott, D. D.; Masel, R. I. In situ spectroscopic examination of a low overpotential pathway for carbon dioxide conversion to carbon monoxide. J. Phys. Chem. C 2012, 116, 1530715312.

(31) Sun, L.; Ramesha, G. K.; Kamat, P. V.; Brennecke, J. F. Switching the reaction course of electrochemical $\mathrm{CO} 2$ reduction with ionic liquids. Langmuir 2014, 30, 6302-6308.

(32) Tanner, E. E.; Batchelor-McAuley, C.; Compton, R. G. Carbon dioxide reduction in room-temperature ionic liquids: the effect of the choice of electrode material, cation, and anion. J. Phys. Chem. C 2016, 120, 26442-26447.

(33) Wang, Y.; Hatakeyama, M.; Ogata, K.; Wakabayashi, M.; Jin, F.; Nakamura, S. Activation of $\mathrm{CO} 2$ by ionic liquid EMIM-BF4 in the electrochemical system: a theoretical study. Phys. Chem. Chem. Phys. 2015, 17, 23521-23531.

(34) Seshadri, G.; Lin, C.; Bocarsly, A. B. A new homogeneous electrocatalyst for the reduction of carbon dioxide to methanol at low overpotential. J. Electroanal. Chem. 1994, 372, 145-150.

(35) Barton Cole, E.; Lakkaraju, P. S.; Rampulla, D. M.; Morris, A. J.; Abelev, E.; Bocarsly, A. B. Using a one-electron shuttle for the multielectron reduction of $\mathrm{CO} 2$ to methanol: kinetic, mechanistic, and structural insights. J. Am. Chem. Soc. 2010, 132, 11539-11551. 
(36) Lee, J. H.; Lauw, S. J.; Webster, R. D. The electrochemical reduction of carbon dioxide $(\mathrm{CO} 2)$ to methanol in the presence of pyridoxine (vitamin B6). Electrochem. Commun. 2016, 64, 69-73.

(37) Pérez-Gallent, E.; Marcandalli, G.; Figueiredo, M. C.; CalleVallejo, F.; Koper, M. T. Structure-and potential-dependent cation effects on $\mathrm{CO}$ reduction at copper single-crystal electrodes. J. Am. Chem. Soc. 2017, 139, 16412-16419.

(38) Resasco, J.; Chen, L. D.; Clark, E.; Tsai, C.; Hahn, C.; Jaramillo, T. F.; Chan, K.; Bell, A. T. Promoter effects of alkali metal cations on the electrochemical reduction of carbon dioxide. J. Am. Chem. Soc. 2017, 139, 11277-11287.

(39) Li, J.; Wu, D.; Malkani, A. S.; Chang, X.; Cheng, M.-J.; Xu, B.; $\mathrm{Lu}, \mathrm{Q}$. Hydroxide is not a promoter of $\mathrm{C} 2+$ product formation in the electrochemical reduction of $\mathrm{CO}$ on copper. Angew. Chem. 2020, 132, 4494-4499.

(40) Lee, M.-Y.; Ringe, S.; Kim, H.; Kang, S.; Kwon, Y. Electric field mediated selectivity switching of electrochemical $\mathrm{CO} 2$ reduction from formate to CO on carbon supported Sn. ACS Energy Lett. 2020, 2987-2994.

(41) Ringe, S.; Morales-Guio, C. G.; Chen, L. D.; Fields, M.; Jaramillo, T. F.; Hahn, C.; Chan, K. Double layer charging driven carbon dioxide adsorption limits the rate of electrochemical carbon dioxide reduction on Gold. Nat. Commun. 2020, 11, No. 33.

(42) Ovalle, V. J.; Waegele, M. M. Impact of electrolyte anions on the adsorption of $\mathrm{CO}$ on $\mathrm{Cu}$ electrodes. J. Phys. Chem. C 2020, 124, 14713-14721.

(43) Banerjee, S.; Zhang, Z.-Q.; Hall, A. S.; Thoi, V. S. Surfactant perturbation of cation interactions at the electrode-electrolyte interface in carbon dioxide reduction. ACS Catal. 2020, 9907-9914.

(44) Bi, W.; Li, X.; You, R.; Chen, M.; Yuan, R.; Huang, W.; Wu, X.; Chu, W.; Wu, C.; Xie, Y. Surface immobilization of transition metal ions on nitrogen-doped graphene realizing high-efficient and selective CO2 reduction. Adv. Mater. 2018, 30, No. 1706617.

(45) Sato, S.; Saita, K.; Sekizawa, K.; Maeda, S.; Morikawa, T. Lowenergy electrocatalytic $\mathrm{CO} 2$ reduction in water over Mn-complex catalyst electrode aided by a nanocarbon support and $\mathrm{K}+$ cations. ACS Catal. 2018, 8, 4452-4458.

(46) Zhang, Z.-Q.; Banerjee, S.; Thoi, V. S.; Shoji Hall, A. Reorganization of Interfacial Water by an Amphiphilic Cationic Surfactant Promotes CO2 Reduction. J. Phys. Chem. Lett. 2020, 11, 5457-5463.

(47) Tomisaki, M.; Natsui, K.; Ikemiya, N.; Nakata, K.; Einaga, Y. Influence of electrolyte on the electrochemical reduction of carbon dioxide using boron-doped diamond electrodes. ChemistrySelect 2018, 3, 10209-10213.

(48) Danilovic, N.; Subbaraman, R.; Strmcnik, D.; Paulikas, A.; Myers, D.; Stamenkovic, V.; Markovic, N. The effect of noncovalent interactions on the HOR, ORR, and HER on Ru, Ir, and Ru 0.50 Ir 0.50 metal surfaces in alkaline environments. Electrocatalysis 2012, 3, 221-229.

(49) Strmcnik, D.; Kodama, K.; Van der Vliet, D.; Greeley, J.; Stamenkovic, V. R.; Marković, N. The role of non-covalent interactions in electrocatalytic fuel-cell reactions on platinum. Nat. Chem. 2009, 1, 466.

(50) Weber, D.; Janssen, M.; Oezaslan, M. Effect of monovalent cations on the HOR/HER activity for Pt in alkaline environment. J. Electrochem. Soc. 2019, 166, F66-F73.

(51) Suntivich, J.; Perry, E. E.; Gasteiger, H. A.; Shao-Horn, Y. The influence of the cation on the oxygen reduction and evolution activities of oxide surfaces in alkaline electrolyte. Electrocatalysis 2013, 4, 49-55.

(52) Angelucci, C. A.; Varela, H.; Tremiliosi-Filho, G.; Gomes, J. F. The significance of non-covalent interactions on the electro-oxidation of alcohols on $\mathrm{Pt}$ and $\mathrm{Au}$ in alkaline media. Electrochem. Commun. 2013, 33, 10-13.

(53) Strmcnik, D.; Van Der Vliet, D.; Chang, K.-C.; Komanicky, V.; Kodama, K.; You, H.; Stamenkovic, V.; Marković, N. Effects of Li+, K + , and $\mathrm{Ba} 2+$ cations on the ORR at model and high surface area $\mathrm{Pt}$ and Au surfaces in alkaline solutions. J. Phys. Chem. Lett. 2011, 2, $2733-2736$

(54) Barnes, A. S.; Rogers, E. I.; Streeter, I.; Aldous, L.; Hardacre, C.; Wildgoose, G. G.; Compton, R. G. Unusual voltammetry of the reduction of $\mathrm{O} 2$ in $[\mathrm{C} 4 \mathrm{dmim}][\mathrm{N}(\mathrm{Tf}) 2]$ reveals a strong interaction of O2•- with the [C4dmim]+ cation. J. Phys. Chem. C 2008, 112, 13709-13715.

(55) Islam, M. M.; Ohsaka, T. Roles of ion pairing on electroreduction of dioxygen in imidazolium-cation-based roomtemperature ionic liquid. J. Phys. Chem. C 2008, 112, 1269-1275.

(56) Siepmann, J. I.; Sprik, M. Influence of surface topology and electrostatic potential on water/electrode systems. J. Chem. Phys. 1995, 102, 511-524.

(57) Willard, A. P.; Reed, S. K.; Madden, P. A.; Chandler, D. Water at an electrochemical interface - a simulation study. Faraday Discuss. 2009, 141, 423-441.

(58) Limmer, D. T.; Willard, A. P.; Madden, P. A.; Chandler, D. Water exchange at a hydrated platinum electrode is rare and collective. J. Phys. Chem. C 2015, 119, 24016-24024.

(59) Limmer, D. T.; Willard, A. P.; Madden, P.; Chandler, D. Hydration of metal surfaces can be dynamically heterogeneous and hydrophobic. Proc. Natl. Acad. Sci. U.S.A. 2013, 110, 4200-4205.

(60) Steinmann, S. N.; Ferreira de Morais, R.; Götz, A. W.; FleuratLessard, P.; Iannuzzi, M.; Sautet, P.; Michel, C. A force field for water over $\mathrm{Pt}(111)$ : Development, assessment and comparison. J. Chem. Theory Comput. 2018, 3238-3251.

(61) Bonthuis, D. J.; Netz, R. R. Beyond the continuum: How molecular solvent structure affects electrostatics and hydrodynamics at solid-electrolyte interfaces. J. Phys. Chem. B 2013, 117, 1139711413.

(62) Bonthuis, D. J.; Netz, R. R. Unraveling the combined effects of dielectric and viscosity profiles on surface capacitance, electro-osmotic mobility, and electric surface conductivity. Langmuir 2012, 28, 16049-16059.

(63) Merlet, C.; Limmer, D. T.; Salanne, M.; Van Roij, R.; Madden, P. A.; Chandler, D.; Rotenberg, B. The electric double layer has a life of its own. J. Phys. Chem. C 2014, 118, 18291-18298.

(64) Lim, H.-K.; Kwon, Y.; Kim, H. S.; Jeon, J.; Kim, Y.-H.; Lim, J.A.; Kim, B.-S.; Choi, J.; Kim, H. Insight into the microenvironments of the metal-ionic liquid interface during electrochemical $\mathrm{CO} 2$ reduction. ACS Catal. 2018, 8, 2420-2427.

(65) Groß, A.; Gossenberger, F.; Lin, X.; Naderian, M.; Sakong, S.; Roman, T. Water structures at metal electrodes studied by ab initio molecular dynamics simulations. J. Electrochem. Soc. 2014, 161, E3015-E3020.

(66) Sakong, S.; Forster-Tonigold, K.; Groß, A. The structure of water at a $\mathrm{Pt}(111)$ electrode and the potential of zero charge studied from first principles. J. Chem. Phys. 2016, 144, No. 194701.

(67) Le, J.; Iannuzzi, M.; Cuesta, A.; Cheng, J. Determining potentials of zero charge of metal electrodes versus the standard hydrogen electrode from density-functional-theory-based molecular dynamics. Phys. Rev. Lett. 2017, 119, No. 016801.

(68) Velasco-Velez, J.-J.; Wu, C. H.; Pascal, T. A.; Wan, L. F.; Guo, J.; Prendergast, D.; Salmeron, M. The structure of interfacial water on gold electrodes studied by $\mathrm{x}$-ray absorption spectroscopy. Science 2014, 346, 831-834.

(69) Björketun, M. E.; Zeng, Z.; Ahmed, R.; Tripkovic, V.; Thygesen, K. S.; Rossmeisl, J. Avoiding pitfalls in the modeling of electrochemical interfaces. Chem. Phys. Lett. 2013, 555, 145-148.

(70) Hansen, M. H.; Rossmeisl, J. pH in grand canonical statistics of an electrochemical interface. J. Phys. Chem. C 2016, 120, 2913529143.

(71) Hansen, M. H.; Nilsson, A.; Rossmeisl, J. Modelling pH and potential in dynamic structures of the water $/ \mathrm{Pt}(111)$ interface on the atomic scale. Phys. Chem. Chem. Phys. 2017, 19, 23505-23514.

(72) Ikeshoji, T.; Otani, M.; Hamada, I.; Sugino, O.; Morikawa, Y.; Okamoto, Y.; Qian, Y.; Yagi, I. The charged interface between Pt and water: First principles molecular dynamics simulations. AIP Adv. 2012, 2, No. 032182. 
(73) Rossmeisl, J.; Skúlason, E.; Björketun, M. E.; Tripkovic, V.; Nørskov, J. K. Modeling the electrified solid-liquid interface. Chem. Phys. Lett. 2008, 466, 68-71.

(74) Kim, Y.; Noh, C.; Jung, Y.; Kang, H. The nature of hydrated protons on platinum surfaces. Chem. - Eur. J. 2017, 23, 17566-17575.

(75) Herron, J. A.; Morikawa, Y.; Mavrikakis, M. Ab initio molecular dynamics of solvation effects on reactivity at electrified interfaces. Proc. Natl. Acad. Sci. U.S.A. 2016, 113, E4937-E4945.

(76) Kristoffersen, H. H.; Vegge, T.; Hansen, H. A. OH formation and $\mathrm{H} 2$ adsorption at the liquid water-Pt (111) interface. Chem. Sci. 2018, 9, 6912-6921.

(77) Heenen, H. H.; Gauthier, J. A.; Kristoffersen, H. H.; Ludwig, T.; Chan, K. Solvation at metal/water interfaces: An ab initio molecular dynamics benchmark of common computational approaches. J. Chem. Phys. 2020, 152, No. 144703.

(78) Saleheen, M.; Heyden, A. Liquid-phase modeling in heterogeneous catalysis. ACS Catal. 2018, 8, 2188-2194.

(79) Behtash, S.; Lu, J.; Faheem, M.; Heyden, A. Solvent effects on the hydrodeoxygenation of propanoic acid over $\mathrm{Pd}(111)$ model surfaces. Green Chem. 2014, 16, 605-616.

(80) Sakong, S.; Naderian, M.; Mathew, K.; Hennig, R. G.; Groß, A. Density functional theory study of the electrochemical interface between a Pt electrode and an aqueous electrolyte using an implicit solvent method. J. Chem. Phys. 2015, 142, No. 234107.

(81) Hörmann, N. G.; Andreussi, O.; Marzari, N. Grand canonical simulations of electrochemical interfaces in implicit solvation models. J. Chem. Phys. 2019, 150, No. 041730.

(82) Steinmann, S. N.; Sautet, P.; Michel, C. Solvation free energies for periodic surfaces: comparison of implicit and explicit solvation models. Phys. Chem. Chem. Phys. 2016, 18, 31850-31861.

(83) Melander, M. M.; Kuisma, M. J.; Christensen, T. E. K.; Honkala, K. Grand-canonical approach to density functional theory of electrocatalytic systems: Thermodynamics of solid-liquid interfaces at constant ion and electrode potentials. J. Chem. Phys. 2019, 150, No. 041706.

(84) Petrosyan, S.; Briere, J.-F.; Roundy, D.; Arias, T. Joint Densityfunctional theory for electronic structure of solvated systems. Phys. Rev. B 2007, 75, No. 205105.

(85) Nishihara, S.; Otani, M. Hybrid solvation models for bulk, interface, and membrane: Reference interaction site methods coupled with density functional theory. Phys. Rev. B 2017, 96, No. 115429.

(86) Andreussi, O.; Dabo, I.; Marzari, N. Revised self-consistent continuum solvation in electronic-Structure calculations. J. Chem. Phys. 2012, 136, No. 064102.

(87) Lozovoi, A.; Alavi, A.; Kohanoff, J.; Lynden-Bell, R. Ab initio simulation of charged slabs at constant chemical potential. J. Chem. Phys. 2001, 115, 1661-1669.

(88) Gauthier, J. A.; Ringe, S.; Dickens, C. F.; Garza, A. J.; Bell, A. T.; Head-Gordon, M.; Nørskov, J. K.; Chan, K. Challenges in modeling electrochemical reaction energetics with polarizable continuum models. ACS Catal. 2019, 9, 920-931.

(89) Otani, M.; Sugino, O. First-principles calculations of charged surfaces and interfaces: A plane-wave nonrepeated slab approach. Phys. Rev. B 2006, 73, No. 115407.

(90) Skúlason, E.; Karlberg, G. S.; Rossmeisl, J.; Bligaard, T.; Greeley, J.; Jónsson, H.; Nørskov, J. K. Density functional theory calculations for the hydrogen evolution reaction in an electrochemical double layer on the Pt (111) electrode. Phys. Chem. Chem. Phys. 2007, 9, 3241-3250.

(91) Skúlason, E.; Tripkovic, V.; Björketun, M. E.; Gudmundsdottir, S.; Karlberg, G.; Rossmeisl, J.; Bligaard, T.; Jónsson, H.; Nørskov, J. K. Modeling the electrochemical hydrogen oxidation and evolution reactions on the basis of density functional theory calculations. J. Phys. Chem. C 2010, 114, 18182-18197.

(92) Schlexer Lamoureux, P.; Singh, A. R.; Chan, K. pH effects on hydrogen evolution and oxidation over $\mathrm{Pt}$ (111): Insights from first principles. ACS Catal. 2019, 6194-6201.

(93) Van den Bossche, M.; Skúlason, E.; Rose-Petruck, C.; Jónsson, $\mathrm{H}$. Assessment of constant-potential implicit solvation calculations of electrochemical energy barriers for $\mathrm{H} 2$ evolution on Pt. J. Phys. Chem. C 2019, 123, 4116-4124.

(94) Chan, K.; Nørskov, J. K. Electrochemical barriers made simple. J. Phys. Chem. Lett. 2015, 6, 2663-2668.

(95) Chan, K.; Nørskov, J. K. Potential dependence of electrochemical barriers from ab initio calculations. J. Phys. Chem. Lett. 2016, 7, 1686-1690.

(96) Gauthier, J. A.; Dickens, C. F.; Chen, L. D.; Doyle, A. D.; Nørskov, J. K. Solvation effects for oxygen evolution reaction catalysis on IrO2 (110). J. Phys. Chem. C 2017, 121, 11455-11463.

(97) Ping, Y.; Nielsen, R. J.; Goddard, W. A., III The reaction mechanism with free energy barriers at constant potentials for the oxygen evolution reaction at the $\mathrm{IrO} 2$ (110) surface. J. Am. Chem. Soc. 2017, 139, 149-155.

(98) He, Z.-D.; Hanselman, S.; Chen, Y.-X.; Koper, M. T.; CalleVallejo, F. Importance of solvation for the accurate prediction of oxygen reduction activities of Pt-based electrocatalysts. J. Phys. Chem. Lett. 2017, 2243-2246.

(99) Calle-Vallejo, F.; F. de Morais, R.; Illas, F.; Loffreda, D.; Sautet, P. Affordable estimation of solvation contributions to the adsorption energies of oxygenates on metal nanoparticles. J. Phys. Chem. C 2019, $123,5578-5582$.

(100) Hyman, M. P.; Medlin, J. W. Theoretical study of the adsorption and dissociation of oxygen on Pt (111) in the presence of homogeneous electric fields. J. Phys. Chem. B 2005, 109, 6304-6310.

(101) Karlberg, G.; Rossmeisl, J.; Nørskov, J. K. Estimations of electric field effects on the oxygen reduction reaction based on the density functional theory. Phys. Chem. Chem. Phys. 2007, 9, 51585161.

(102) Kelly, S. R.; Kirk, C.; Chan, K.; Nørskov, J. K. Electric field effects in oxygen reduction kinetics: Rationalizing $\mathrm{pH}$ dependence at the $\mathrm{Pt}(111), \mathrm{Au}(111)$ and $\mathrm{Au}(100)$ electrodes. J. Phys. Chem. C 2020, 14581-14591.

(103) Steinmann, S. N.; Michel, C.; Schwiedernoch, R; Sautet, P. Impacts of electrode potentials and solvents on the electroreduction of CO2: a comparison of theoretical approaches. Phys. Chem. Chem. Phys. 2015, 17, 13949-13963.

(104) Chen, L. D.; Urushihara, M.; Chan, K.; Nørskov, J. K. Electric field effects in electrochemical $\mathrm{CO} 2$ reduction. ACS Catal. 2016, 6, 7133-7139.

(105) Jiang, K.; Sandberg, R. B.; Akey, A. J.; Liu, X.; Bell, D. C.; Nørskov, J. K.; Chan, K.; Wang, H. Metal ion cycling of $\mathrm{Cu}$ foil for selective $\mathrm{C}-\mathrm{C}$ coupling in electrochemical CO 2 reduction. Nat. Catal. 2018, 1, 111.

(106) Montoya, J. H.; Peterson, A. A.; Nørskov, J. K. Insights into C$\mathrm{C}$ Coupling in $\mathrm{CO} 2$ electroreduction on copper electrodes. ChemCatChem 2013, 5, 737-742.

(107) Montoya, J. H.; Shi, C.; Chan, K.; Nørskov, J. K. Theoretical insights into a $\mathrm{CO}$ dimerization mechanism in $\mathrm{CO} 2$ electroreduction. J. Phys. Chem. Lett. 2015, 6, 2032-2037.

(108) Sandberg, R. B.; Montoya, J. H.; Chan, K.; Nørskov, J. K. CO$\mathrm{CO}$ coupling on $\mathrm{Cu}$ facets: Coverage, strain and field effects. Surf. Sci. 2016, 654, 56-62.

(109) Cheng, T.; Xiao, H.; Goddard, W. A. Full atomistic reaction mechanism with kinetics for $\mathrm{CO}$ reduction on $\mathrm{Cu}(100)$ from $\mathrm{ab}$ initio molecular dynamics free-energy calculations at $298 \mathrm{~K}$. Proc. Natl. Acad. Sci. U.S.A. 2017, 114, 1795-1800.

(110) Bagger, A.; Arnarson, L.; Hansen, M. H.; Spohr, E.; Rossmeisl, J. Electrochemical CO reduction: A property of the electrochemical interface. J. Am. Chem. Soc. 2019, 141, 1506-1514.

(111) Liu, M.; Pang, Y.; Zhang, B.; De Luna, P.; Voznyy, O.; Xu, J.; Zheng, X.; Dinh, C. T.; Fan, F.; Cao, C.; et al. Enhanced electrocatalytic $\mathrm{CO} 2$ reduction via field-induced reagent concentration. Nature 2016, 537, 382.

(112) Hussain, J.; Jónsson, H.; Skúlason, E. Calculations of product selectivity in electrochemical CO2 reduction. ACS Catal. 2018, 8, $5240-5249$. 
(113) Akhade, S. A.; McCrum, I. T.; Janik, M. J. The impact of specifically adsorbed ions on the copper-catalyzed electroreduction of CO2. J. Electrochem. Soc. 2016, 163, F477-F484.

(114) Ringe, S.; Clark, E. L.; Resasco, J.; Walton, A.; Seger, B.; Bell, A. T.; Chan, K. Understanding cation effects in electrochemical CO2 reduction. Energy Environ. Sci. 2019, 3001-3014.

(115) Lau, G. P.; Schreier, M.; Vasilyev, D.; Scopelliti, R.; Grätzel, M.; Dyson, P. J. New insights into the role of imidazolium-based promoters for the electroreduction of $\mathrm{CO} 2$ on a silver electrode. J. Am. Chem. Soc. 2016, 138, 7820-7823.

(116) Snuffin, L. L.; Whaley, L. W.; Yu, L. Catalytic electrochemical reduction of $\mathrm{CO} 2$ in ionic liquid EMIMBF3Cl. J. Electrochem. Soc. 2011, 158, F155-F158.

(117) Qiu, Y.; Zhong, H.; Xu, W.; Zhang, T.; Li, X.; Zhang, H. Tuning the electrocatalytic properties of a $\mathrm{Cu}$ electrode with organic additives containing amine group for $\mathrm{CO} 2$ reduction. J. Mater. Chem. A 2019, 7, 5453-5462.

(118) Chen, L. D.; Bajdich, M.; Martirez, J. M. P.; Krauter, C. M.; Gauthier, J. A.; Carter, E. A.; Luntz, A. C.; Chan, K.; Nørskov, J. K. Understanding the apparent fractional charge of protons in the aqueous electrochemical double layer. Nat. Commun. 2018, 9, No. 3202.

(119) Anderson, M. R.; Huang, J. The influence of cation size upon the infrared spectrum of carbon monoxide adsorbed on platinum electrodes. J. Electroanal. Chem. Interfacial Electrochem. 1991, 318, 335-347.

(120) Gunathunge, C. M.; Ovalle, V. J.; Waegele, M. M. Probing promoting effects of alkali cations on the reduction of $\mathrm{CO}$ at the aqueous electrolyte/copper interface. Phys. Chem. Chem. Phys. 2017, 19, 30166-30172.

(121) Goedecker, S. Minima hopping: An efficient search method for the global minimum of the potential energy surface of complex molecular systems. J. Chem. Phys. 2004, 120, 9911-9917.

(122) Peterson, A. A. Global optimization of adsorbate-surface structures while preserving molecular identity. Top. Catal. 2014, 57, $40-53$.

(123) Giannozzi, P.; Baroni, S.; Bonini, N.; Calandra, M.; Car, R.; Cavazzoni, C.; Ceresoli, D.; Chiarotti, G. L.; Cococcioni, M.; Dabo, I.; et al. QUANTUM ESPRESSO: a modular and open-source software project for quantum simulations of materials. J. Phys.: Condens. Matter 2009, 21, No. 395502.

(124) Larsen, A. H.; Mortensen, J. J.; Blomqvist, J.; Castelli, I. E.; Christensen, R.; Dułak, M.; Friis, J.; Groves, M. N.; Hammer, B.; Hargus, C.; et al. The atomic simulation environment-a Python library for working with atoms. J. Phys.: Condens. Matter 2017, 29, No. 273002.

(125) Vanderbilt, D. Soft self-consistent pseudopotentials in a generalized eigenvalue formalism. Phys. Rev. B 1990, 41, 7892-7895.

(126) Laasonen, K.; Car, R.; Lee, C.; Vanderbilt, D. Implementation of ultrasoft pseudopotentials in ab initio molecular dynamics. Phys. Rev. B 1991, 43, 6796-6799.

(127) Laasonen, K.; Pasquarello, A.; Car, R.; Lee, C.; Vanderbilt, D. Car-Parrinello molecular dynamics with Vanderbilt ultrasoft pseudopotentials. Phys. Rev. B 1993, 47, 10142-10153.

(128) Garrity, K. F.; Bennett, J. W.; Rabe, K. M.; Vanderbilt, D. Pseudopotentials for high-throughput DFT calculations. Comput. Mater. Sci. 2014, 81, 446-452.

(129) Wellendorff, J.; Lundgaard, K. T.; Møgelhøj, A.; Petzold, V.; Landis, D. D.; Nørskov, J. K.; Bligaard, T.; Jacobsen, K. W. Density functionals for surface science: Exchange-correlation model development with Bayesian error estimation. Phys. Rev. B 2012, 85, No. 235149.

(130) Dion, M.; Rydberg, H.; Schröder, E.; Langreth, D. C.; Lundqvist, B. I. Van der Waals density functional for general geometries. Phys. Rev. Lett. 2004, 92, No. 246401.

(131) Thonhauser, T.; Cooper, V. R.; Li, S.; Puzder, A.; Hyldgaard, P.; Langreth, D. C. Van der Waals density functional: Self-consistent potential and the nature of the van der Waals bond. Phys. Rev. B 2007, 76, No. 125112.
(132) Román-Pérez, G.; Soler, J. M. Efficient implementation of a Van der Waals Density Functional: Application to double-wall carbon nanotubes. Phys. Rev. Lett. 2009, 103, No. 096102.

(133) Monkhorst, H. J.; Pack, J. D. Special points for Brillouin-zone integrations. Phys. Rev. B 1976, 13, 5188-5192.

(134) Ludwig, T.; Gauthier, J. A.; Brown, K. S.; Ringe, S.; Norskov, J. K.; Chan, K. Solvent-adsorbate interactions and adsorbate-specific solvent structure in carbon dioxide reduction on a stepped $\mathrm{Cu}$ surface. J. Phys. Chem. C 2019, 5999-6009.

(135) DeLano, W. L. PyMOL, 2002.

(136) Humphrey, W.; Dalke, A.; Schulten, K. VMD - Visual Molecular Dynamics. J. Mol. Graphics 1996, 14, 33-38.

(137) Manz, T. A. Introducing DDEC6 atomic population analysis: Part 3. Comprehensive method to compute bond orders. RSC Adv. 2017, 7, 45552-45581.

(138) Limas, N. G.; Manz, T. A. Introducing DDEC6 atomic population analysis: Part 2 . Computed results for a wide range of periodic and nonperiodic materials. RSC Adv. 2016, 6, 45727-45747.

(139) Mortensen, J. J.; Hansen, L. B.; Jacobsen, K. W. Real-space grid implementation of the projector augmented wave method. Phys. Rev. B 2005, 71, No. 035109.

(140) Enkovaara, J.; Rostgaard, C.; Mortensen, J. J.; Chen, J.; Dułak, M.; Ferrighi, L.; Gavnholt, J.; Glinsvad, C.; Haikola, V.; Hansen, H. A.; et al. Electronic structure calculations with GPAW: A real-space implementation of the projector augmented-wave method. J. Phys.: Condens. Matter 2010, 22, No. 253202.

(141) Varma, S.; Rempe, S. B. Coordination numbers of alkali metal ions in aqueous solutions. Biophys. Chem. 2006, 124, 192-199.

(142) Mähler, J.; Persson, I. A study of the hydration of the alkali metal ions in aqueous solution. Inorg. Chem. 2012, 51, 425-438.

(143) Toney, M. F.; Howard, J. N.; Richer, J.; Borges, G. L.; Gordon, J. G.; Melroy, O. R.; Wiesler, D. G.; Yee, D.; Sorensen, L. B. Voltage-dependent ordering of water molecules at an electrodeelectrolyte interface. Nature 1994, 368, 444-446.

(144) Garcia-Araez, N.; Climent, V.; Feliu, J. Potential-dependent water orientation on $\mathrm{Pt}(111), \mathrm{Pt}(100)$, and $\mathrm{Pt}$ (110), as inferred from laser-pulsed experiments. Electrostatic and chemical effects. $J$. Phys. Chem. C 2009, 113, 9290-9304.

(145) Sakong, S.; Groß, A. Water structures on a Pt (111) electrode from ab initio molecular dynamic simulations for a variety of electrochemical conditions. Phys. Chem. Chem. Phys. 2020, 22, 10431-10437.

(146) Eukomska, A.; Sobkowski, J. Potential of zero charge of monocrystalline copper electrodes in perchlorate solutions. $J$. Electroanal. Chem. 2004, 567, 95-102.

(147) The absolute electrode potential: an explanatory note (Recommendations 1986). J. Electroanal. Chem. Interfacial Electrochem. 1986, 209, 417 428. DOI: 10.1016/0022-0728(86)80570-8.

(148) Gauthier, J. A.; Dickens, C. F.; Heenen, H. H.; Vijay, S.; Ringe, S.; Chan, K. Unified approach to implicit and explicit solvent simulations of electrochemical reaction energetics. J. Chem. Theory Comput. 2019, 15, 6895-6906.

(149) Henkelman, G.; Arnaldsson, A.; Jónsson, H. A fast and robust algorithm for Bader decomposition of charge density. Comput. Mater. Sci. 2006, 36, 354-360.

(150) Sanville, E.; Kenny, S. D.; Smith, R.; Henkelman, G. Improved grid-based algorithm for Bader charge allocation. J. Comput. Chem. 2007, 28, 899-908.

(151) Yu, M.; Trinkle, D. R. Accurate and efficient algorithm for Bader charge integration. J. Chem. Phys. 2011, 134, No. 06411.

(152) Tang, W.; Sanville, E.; Henkelman, G. A grid-based Bader analysis algorithm without lattice bias. J. Phys.: Condens. Matter 2009, 21, No. 084204. 